\title{
Free Surface Multiple Removal Using 3D Surface Related Multiple Elimination Technique on 3D Seismic Data from Offshore Niger Delta
}

\author{
Ogagarue D.O. ${ }^{1, *}$, Nwankwo C.N ${ }^{2}$ \\ ${ }^{1}$ Department of Earth Sciences, Federal University of Petroleum Resources, Effurun, Nigeria \\ ${ }^{2}$ Department of Physics, University of Port Harcourt, Nigeria \\ *Corresponding author: ogagarue.odeyovwi@fupre.edu.ng
}

Received January 03, 2019; Revised February 05, 2019; Accepted February 12, 2019

\begin{abstract}
In addition to de-spiking, gun delay correction, correction for spherical spreading and earth's absorption, gun and cable correction, zero-phasing, noise attenuation and correction for time shifts between sail lines due to changes in velocity of the water column, multiple elimination is the other important true relative amplitude processing routine desired to produce seismic gathers consistent with DHI and AVO analysis to de-risk the presence of hydrocarbon interpreted from seismic data. Multiple problems associated with seismic data acquired in the Niger Delta offshore are those due mainly to the free air-water interface and the seabed, and their presence constitute noise in the seismic dataset. In this study, we employed an approach in which we convolved all possible source and receiver peglegs for every multiple event that strikes the free surface irrespective of its path in the subsurface to model the multiple wave field in a 3D sense, in a partially processed pre-migration seismic data acquired in the Niger Delta deep offshore. The method of adaptive subtraction was then used to eliminate the modeled multiples from the dataset. Un-like other demultiple techniques such as tau-p deconvolution and radon, our multiple modeling and subtraction techniques do not require prior knowledge of the subsurface geology in terms of the velocity and reflectivity of the multiple wave field. The aim of the study was to improve the overall quality of the seismic data and signal-to-noise ratio, in addition to the DHI and AVO compliant gathers output from the process. The approach was successful and effective in removal of the free, air-water surface multiples from the dataset.
\end{abstract}

Keywords: 3D multiple wave field, demultiple, 3D SRME, true relative amplitude, AVO compliant product, airwater surface multiples

Cite This Article: Ogagarue D.O., and Nwankwo C.N, "Free Surface Multiple Removal Using 3D Surface Related Multiple Elimination Technique on 3D Seismic Data from Offshore Niger Delta." Journal of Geosciences and Geomatics, vol. 7, no. 2 (2019): 66-72. doi: 10.12691/jgg-7-2-2.

\section{Introduction}

Multiple reflections are considered noise in seismic data [1]; they reduce signal-to-noise ratio, interfere identification of primary reflections and cause difficulty in velocity analysis, resulting in spurious seismic images, amplitudes and stratigraphic interpretation uncertainties [2]. It is therefore expedient that they are removed, especially before velocity analysis and/or modeling prior to imaging in order to obtain geologically representative velocity that would give accurate image of the subsurface.

Multiples can be classified as surface related multiples and internal multiples based on where the downward reflection of the raypath occurs [3,4]. Surface related multiples, sometimes referred to as free surface or surface multiples, are multiples that have at least one downward reflection at the free air-water surface in marine and offshore operations. These multiples are due to the large negative reflection coefficient at the free air-water interface, arising from the large acoustic impedance contrast across the interface. They include reflections generated from the water-bottom and reverberations which impact marine and offshore seismic data. Multiples which have all of their downward reflections below the free airwater surface are classified as internal multiples. These multiples strongly affect land data, and only a few techniques exist to eliminate them from the seismic record [5]. They get more attention in marine and offshore operations when imaging subsalt targets.

Several techniques have been employed in the literature to suppress multiples. The various techniques can be divided into three broad groups which include deconvolution, filtering and wave field prediction and subtraction [1] based on criteria to differentiate multiples from primary reflections. The choice of technique largely depends on the effectiveness of the technique in suppressing the multiples, its cost in terms of computation time and objective of the processing. Deconvolution techniques utilize the periodic characteristic of the multiples to predict them, assuming that the interface 
generating the multiples (e.g. the water-bottom) is flat. This assumption could be valid for shallow marine but would most likely fail in deep offshore acquisition where spatial variation in the depth to the water-bottom could be enormous. The deconvolution techniques have been successful in suppressing short period multiples from field data [6-7]. The filtering methods include filtering in the f$\mathrm{k}$ and tau-p domains, and parabolic radon filtering. These methods utilize the differences in moveout to differentiate multiples from the primaries. Differential moveout between primary reflections and multiples is minimal in shallow water acquisitions, but could be quite large for moderate to deepwater data. Consequently, the filtering methods are not suitable for shallow water seismic demultiple but have been successful for moderate to deepwater data $[8,9,10]$. The wave field prediction and subtraction methods predict multiples from either modeling or inversion of the recorded wave field, based on wave equation concepts, and then match and subtract the modeled or inverted multiples from the seismic data $[11,12,13]$, leaving ideally, seismic free of multiple energy. The wave equation methods do not require prior knowledge of the subsurface geology, and do not coincidentally attenuate primary energy in any form and as such, they are most suitable when the processing objective is to preserve relative amplitudes for quantitative seismic interpretation.

Surface related multiples are very dominating multiples in seismic data [2]. Theoretical work on multiple modeling and elimination of these multiples began with the works of $[14,15,16]$ and [17,18] suggested the adaptive approach of eliminating them with application to field data [2]. Success in the application of conventional surface related multiple elimination techniques to 3D seismic data require that the dataset is densely sampled, such that there is a source at every receiver location. Typical marine or offshore acquisitions are often inadequately sampled in the crossline shot direction, and this introduces aliasing in the demultipled data [19] if not addressed. Various strategies have been suggested to address this, such as shot interpolation [20,21,22], interpolation of the missing contributions from the multiple model [23] and dense acquisition, all of which would raise hardware compute capacity and run time and therefore operational costs.

In this paper, we applied the 3D surface related multiple elimination (3D SRME) technique to successfully remove surface multiples from 3D seismic data from offshore Niger Delta. The implementation combines both shot interpolation and extrapolation of near offsets to zero, with no interpolation in the crossline direction which saves compute time and cost.

\section{Basic Theoretical Consideration}

In the presence of a free surface, an up-going wave reflects at the air-water interface (free surface), and is transformed into a down-going wave. In Figure 1a, for example, the free surface multiple SABCR is generated at source $\mathrm{S}$ and received at receiver $\mathrm{R}$ after a bounce at point B on the free surface. Reference [24] presented a method of predicting the free surface multiple by convolution of the sub-events $\mathrm{SAB}$ and BCR (Equation 1), assuming $\mathrm{B}$ is known.

$$
\text { mult }(\mathrm{SABCR})=\mathrm{P}(\mathrm{SAB}) * \mathrm{P}(\mathrm{BCR})
$$

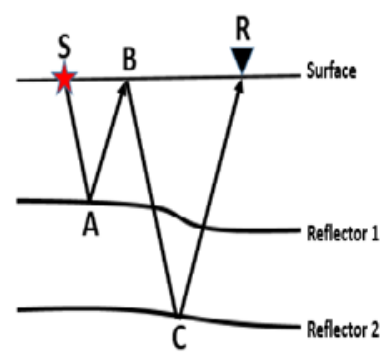

(a)

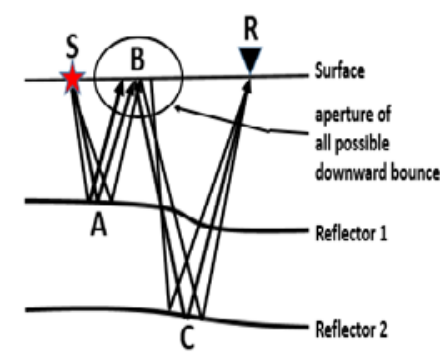

(b)
Figure 1. 3D SRME theory and method (a) Free surface multiple SABCR (modified from [24], in [1] (b) and inclusion of aperture of all possible free surface multiples

Our 3D SRME approach in this paper uses convolution to model the free surface multiples following the [24], but with modification to map an aperture for all possible downward bounce locations on the free surface over which the convolution process is carried out (Figure 1b). The size and shape of this aperture depend on data acquisition geometry and geologic complexity. Using this method, the predicted multiple in Equation 1 becomes the summation of the convolution of all possible sub-events within the pre-determined aperture as shown in Equation 2.

$$
\begin{aligned}
& \sum \mathrm{P}(\mathrm{SAB}) * \mathrm{P}(\mathrm{BCR}), \mathrm{P}\left(\mathrm{SAB}^{\mathrm{I}}\right) \mathrm{P}\left(\mathrm{BCR}^{\mathrm{I}}\right), \\
& \mathrm{P}\left(\mathrm{SAB}^{\mathrm{II}}\right) \mathrm{P}\left(\mathrm{BCR}^{\mathrm{II}}\right), \mathrm{P}\left(\mathrm{SAB}^{\mathrm{n}}\right) * \mathrm{P}\left(\mathrm{BCR}^{\mathrm{n}}\right)
\end{aligned}
$$

where $\mathrm{SAB}^{I, I I,,, n}$ and $\mathrm{BCR}^{I, I I,,,, n}$ are additional, possible sub-events within the multiple area. In this perspective, each multiple is regarded as a combination of primary events to facilitate its prediction. The practical implementation of the above in the offshore dataset used in this study is given in detail in the next section.

\section{Location and Geology}

The study area is located in the western part of the Niger Delta offshore (Figure 2). The area occupied by the present day Niger Delta was the site of a triple junction that formed pre-initiation of the south American plate from the African plate around the bay head of the Gulf of Guinea [25]. The delta receives its sediments from rivers Benue and Niger through the Anambra basin, with major regressive sediments being built up in Tertiary times. Structural styles in the Niger Delta are due to differential loading of the prodelta shales which underlie the deltaic succession. This has been linked to three basic elemental deformations which include megastructure bounding fault in the north, counter-regional terminating fault and/or toe thrust belt in the south and a central rigid block intervening between the two faults systems; these deformational patterns divide the delta into five depobelts, namely, northern delta, greater Ughelli, Central, Coastal and Shallow offshore/offshore depobelt, each of which has common characteristics in terms of charge and 
hydrocarbon occurrence [26]. The Niger Delta is divided into three lithostratigraphic units namely, Benin, Agbada and Akata Formations. The Benin Formation is dominated by fluviatile sands of the Coastal Plain facies of the Niger Delta. Its base is diachronous and ranges in age from Oligocene to Recent [27]. The Agbada Formation consists of alternating sand and shale sequence, and is believed to be the main reservoir unit in the Niger Delta. The Akata Formation, which comprise mainly marine shales with few sand intercalations, underlie the Tertiary Niger Delta. Its age ranges from Eocene to Recent. It is believed to be the major hydrocarbon source rock in the Niger Delta.

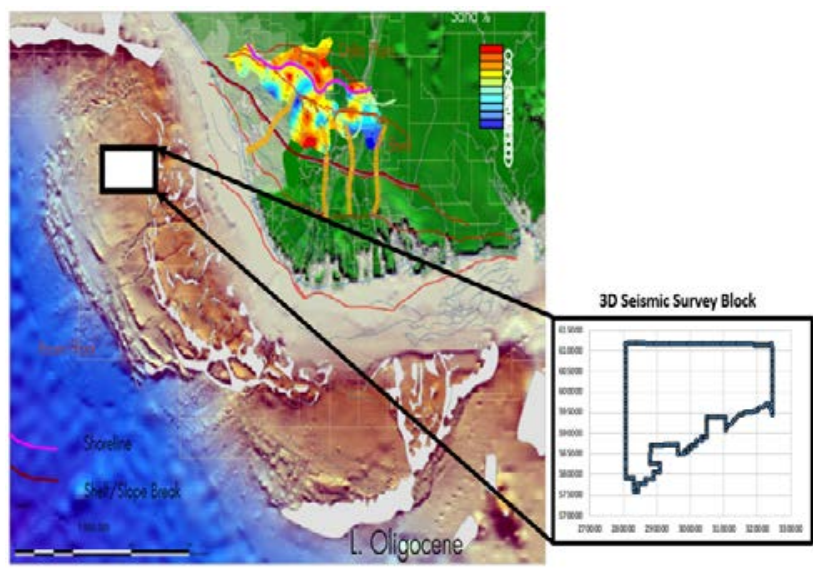

Figure 2. Niger Delta map showing area of study

\section{Materials and Methods}

\subsection{Materials}
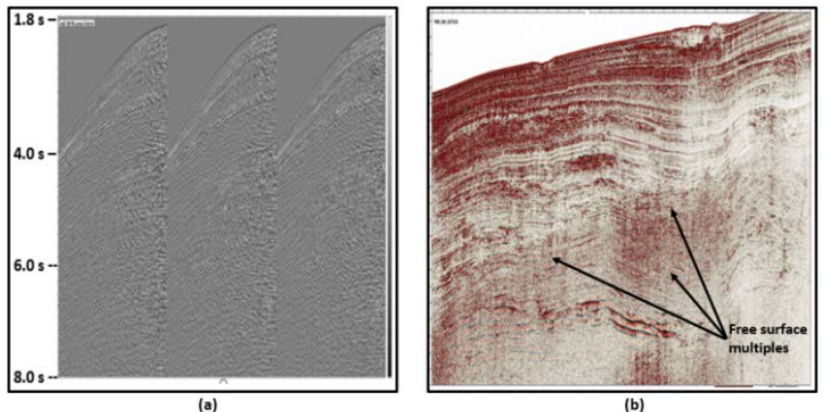

Figure 3. Shot gathers before 3D SRME (a) and 3D stack of shot gathers input to 3D SRME. The display has been zoomed to $1.8 \mathrm{~s}-8.0 \mathrm{~s}$ for the deep offshore dataset.

The input dataset for the 3D SRME comprise approximately $570 \mathrm{~km}^{2}$ fairly processed shot gathers acquired in offshore Niger Delta. The data were acquired at a bin size of $6.25 \mathrm{~m} \times 25 \mathrm{~m}$, using a streamer length of $5 \mathrm{~km}$. Processing objectives were enhancement of signal-to-noise ratio, true relative amplitude products and products consistent with DHI and AVO, potentially to enhance data quality and predict accurate reservoir properties in the area. 3D SRME was key to addressing these issues. Prior signal processing on the dataset include shot and channel amplitude editing, de-spiking, Butterworth band pass filtering, gun timing delay correction, bulk static shift of the data to mean sea level thereby removing the effect of gun and cable depths, true amplitude recovery gain correction, zero-phasing, noise attenuation, water column statics and receiver motion correction. The signal processing was retained at the acquisition sample rate of $2 \mathrm{~ms}$. Figure 3a shows shot gathers input to 3D SRME and Figure 3b shows 3D stack of the input. The stack reveals significant contamination of the data with free surface multiples.

\subsection{Data Preparation}

In the first step of data preparation for the 3D SRME, we created a single cube which contains 50 offsets ranging from $0-5000 \mathrm{~m}$, with an offset spacing of $100 \mathrm{~m}$. This cube contained one trace per bin per offset, and as the data was loaded into the cube, the trace was chosen such that it was the closest to the bin center. Shot interpolation between every shot was also carried out while the data was being loaded into the cube. This was done to infill missing traces and ensure that there was a trace in every bin. Priority was given to the primary (non-interpolated) traces in the trace assignment to the bin center; for every bin where there was an acquired shot, the acquired trace was assigned to the bin while interpolated trace was assigned to a bin only in the case of missing traces.

The second stage of data preparation involved extrapolation of near offsets to 0 , followed by infill of holes or missing traces within an offset using linear tau-p interpolation. Trace infill for this study was limited to not more than 3 traces, and primary area of focus in data interpolation was the water bottom extending down to the top of the first water bottom multiple. No infill was done for holes larger than 3 traces to avoid aliasing. The 3D SRME was carried out at the acquisition grid of $6.25 \mathrm{~m} \mathrm{x}$ $25 \mathrm{~m}$. This bin size was considered adequate for multiple prediction and as such, no crossline interpolation was required.

\subsection{Prediction Aperture}

Optimal apertures for multiple prediction in the inline and crossline directions were determined based on offsets for the near, mid and far channels. The determination of the optimum aperture was predicated on testing on key test sail lines and analysis of multiple contribution gathers for the near $(0-1,500 \mathrm{~m})$, mid $(1,500-2,500 \mathrm{~m})$ and far offsets $(>3,000 \mathrm{~m})$. Apertures of $500-1,500 \mathrm{~m}, 1,500-$ $2,500 \mathrm{~m}$ and greater than 2,500 $\mathrm{m}$ were tested for the near, mid and far offsets respectively and an optimum aperture chosen for the respectively offsets.

\subsection{Multiple Prediction}

Multiple prediction was carried out with the optimum aperture for the near, mid and far offsets. To predict the multiple, every source and receiver combination in a given sequence was split into a source- midpoint wave-path and receiver-midpoint wave-path. These two components were then convolved to generate the multiple model for the midpoint bin for this primary source and receiver. Thereafter, all source and receiver pair traces with the selected aperture for every offset and bin related to the primary are convolved to create the multiple model for the bin/midpoint relating to the primary source and receiver. In other words, the multiple prediction interpolated aperture 
values in-between the near, mid and far offsets in both inline and crossline directions. This could involve thousands of convolutions as shown in Equation 2, so the predicted multiple could be significantly higher in amplitude than the original primary data. The predictions were done for each sequence and multiple model was output for each sequence.

\subsection{Multiple Subtraction}

We used two (2) passes of least squares adaptive subtraction to subtract the predicted multiples from the multiple-contaminated input data. The first pass used a global match over a large time and trace window to correct the predicted multiples so that they match in amplitude and time with the input on a global scale. The second pass was a local adaptive match carried out over a smaller time and trace window whereby the predicted multiple model was adaptively subtracted from the input data. The process was such that for each of the defined time and space window, a temporal filter was designed in order that after convolving this filter with the predicted multiples, the subtraction of the result from the input would yield the multiple-free data.

\section{Results and Discussion}

Figure 4 shows the NMO-corrected input gathers for the 3D SRME, ordered in CDP track, before and after linear tau-p interpolation, preparatory to 3D SRME. Figure 4a shows evidence of hole in the near offsets which were completely filled by the linear tau-p interpolation method used in this study as is shown in Figure 4b. Hole infill and interpolation of near offsets are routine procedures in 3D SRME. The conventional parabolic and $\mathrm{f}-\mathrm{k}$ interpolation methods were applied to the data prior to the linear tau-p methods. Whereas it was observed that the parabolic interpolation was not able to interpolate to zero offset correctly without introducing aliasing in amplitudes, the $\mathrm{f}-\mathrm{k}$ interpolation was optimal only for interpolation of a single trace between primary traces, it introduced linear dip smearing across interpolated events if the number of traces were more (up to 3). The linear tau-p interpolation was observed to be capable of creating a copy of the nearest trace for each near offset bin to populate, in addition to its ability to handle multiple trace interpolation better and as such, it was preferred for this study.
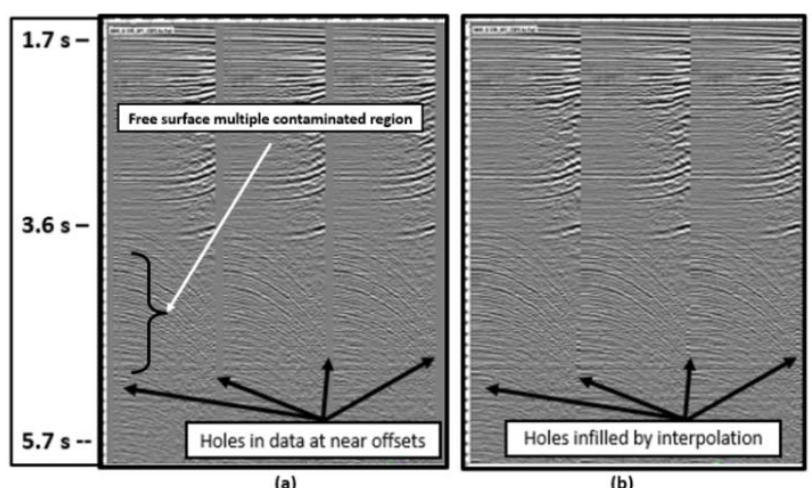

Figure 4. NMO-corrected, CDP track ordered input shot gathers for 3D SRME: (a) gathers before linear tau-p interpolation (b) gathers after linear tau-p interpolation
The 3D SRME multiple modeling tests carried out show that increasing or decreasing the aperture size of the multiple model in the inline direction with respect to the crossline direction or in the crossline direction with respect to the inline direction did not have any additional advantage in the multiple modeling. Consequently, the same aperture size was tested to model the multiples in both directions. Table 1 shows the summary of the result of inline and crossline aperture parameters used for the multiple modeling and Table 2 shows the multiple prediction parameterization. Figure 5 shows a stack of the interpolated shot gathers input for 3D multiple model prediction and a model of the predicted multiples for a test sequence in the study. The figure shows that the 3D SRME approach was effective in free surface multiple prediction in most areas of the survey. Table 3 shows the adaptive predicted 3D multiple subtraction parameterization.

Table 1. Selected parameterization for free surface multiple prediction

\begin{tabular}{|c|c|c|}
\hline Offset Name & Offset (m) & Aperture (Inline/Xline) \\
\hline Near offset & 500 & $1,250 \mathrm{~m} \times 1,250 \mathrm{~m}$ \\
\hline Mid offset & 2,750 & $1,500 \mathrm{~m} \times 1,500 \mathrm{~m}$ \\
\hline Far offset & $\begin{array}{c}4,750 \\
\text { level-3 heading, }\end{array}$ & $2,000 \mathrm{~m} \times 2,000 \mathrm{~m}$ \\
\hline
\end{tabular}

Table 2. 3D SRME multiple prediction parameters

\begin{tabular}{|c|c|}
\hline Parameter & Value \\
\hline Grid size & $6.25 \mathrm{~m} \mathrm{x} \mathrm{25} \mathrm{m}$ \\
\hline Shot interpolation & $2: 1$ \\
\hline Inline/Xline aperture & \\
Near offset & $1,250 \mathrm{~m} \mathrm{x} \mathrm{1,250} \mathrm{m}$ \\
Mid offset & $1,500 \mathrm{~m} \mathrm{x} \mathrm{1,500} \mathrm{m}$ \\
Far offset & $2,000 \mathrm{~m} \mathrm{x} \mathrm{2,000} \mathrm{m}$ \\
\hline
\end{tabular}

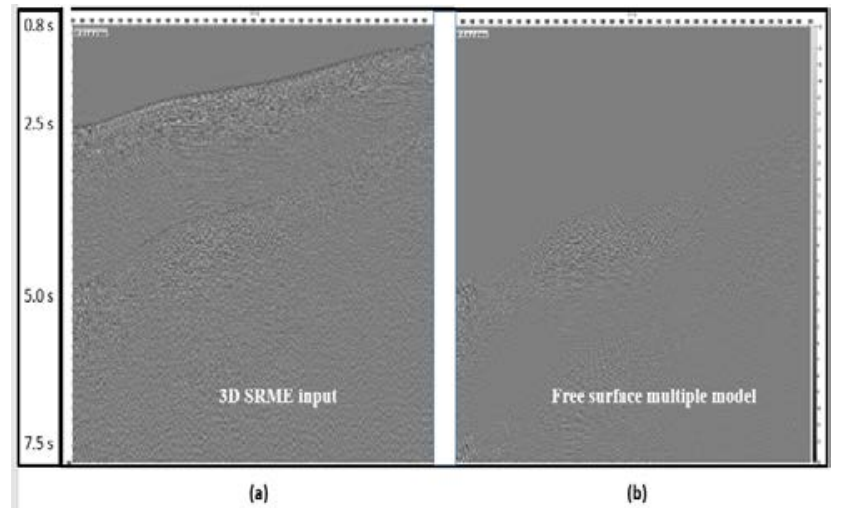

Figure 5. 3D multiple modeled with the parameterization in Table 2 for a test input sequence in the survey

Table 3. Predicted 3D free surface multiples adaptive subtraction parameterization

\begin{tabular}{|c|c|c|c|c|c|}
\hline $\begin{array}{c}\text { Subtraction } \\
\text { /Adaptation }\end{array}$ & Domain & $\begin{array}{c}\text { Frequency } \\
\text { Band (Hz) }\end{array}$ & $\begin{array}{c}\text { Filter } \\
\text { Length } \\
(\mathrm{ms})\end{array}$ & $\begin{array}{c}\text { Time } \\
\text { Window }\end{array}$ & $\begin{array}{c}\text { Spatial } \\
\text { window }\end{array}$ \\
\hline Global & Shot & All & 20 & 1,875 & 400 \\
\hline \multirow{2}{*}{ Local } & Shot & $0-60$ & 12 & 300 & 100 \\
& & $80-88$ & 24 & 300 & 50 \\
& $88-250$ & 30 & 150 & 8 \\
\hline
\end{tabular}




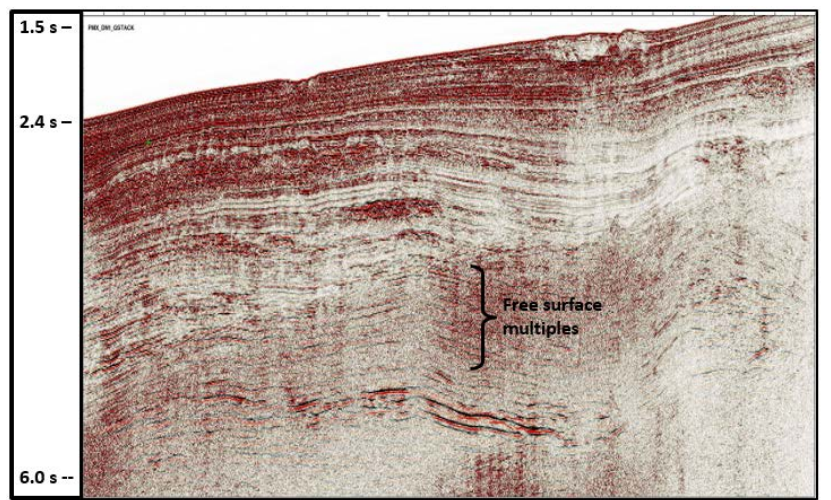

Figure 6a. Inline stack before 3D SRME multiple modeling and adaptive subtraction

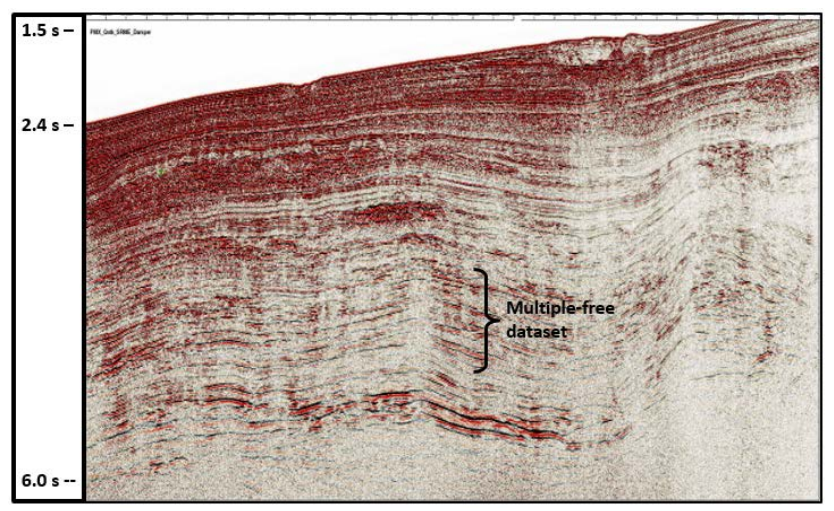

Figure 6b. Inline stack after 3D SRME multiple modeling and adaptive subtraction

Figure 6a shows stack before the 3D SRME adaptive subtraction and Figure 6b shows the stack after the subtraction. The difference between these datasets is a

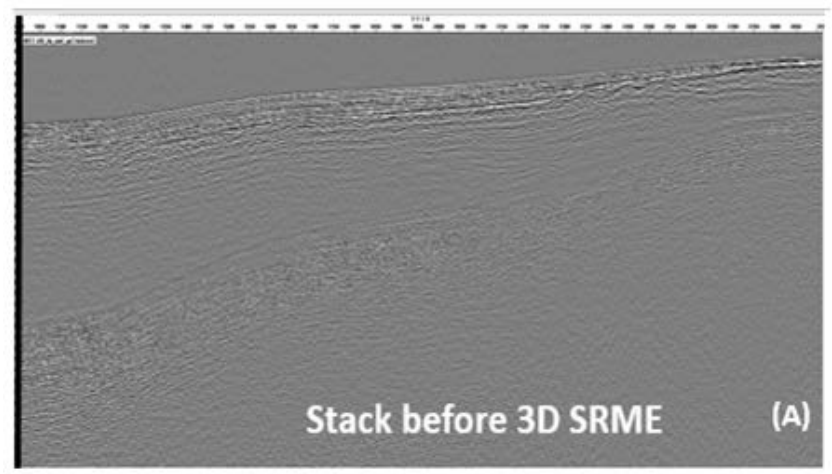

measure of the effectiveness of the multiple suppression technique when compared to the multiple model. The results show good correlation between the difference and the multiple model.

The 3D SRME was effective in attenuating multiples from 0 to $60 \mathrm{~Hz}$. The results, however, show some residual high-frequency multiples above $40 \mathrm{~Hz}$ in the data after application of the 3D SRME. As expected, this occurred mainly around data boundary areas where the 3D SRME had limited aperture. This is a limitation in 3D SRME. To address this issue, we deployed a damper tool which compares free surface multiple amplitudes in frequency panels to amplitudes in a reference window, such that amplitudes in a given sample can be clipped to the amplitude of a reference window if it becomes necessary. This tool was effective in removing the residual free surface multiples in the dataset. Figure 7 shows 2D stack of a given sequence before and after 3D SRME and the result of application of the post 3D SRME free surface multiple removal and Figure 8 shows time slice of the data at $4.5 \mathrm{~s}$ before the 3D SRME and after application of post 3D SRME residual free surface multiple attenuation.

The free surface demultiple technique applied in this study is a primary reflection-conscious-based method of removing free surface multiples as it aims to remove only the multiple energy without impacting primary signals. The true relative amplitudes of the primary signals are preserved, making the method to be DHI and AVO consistent. In addition, the approach ensures full interpolation of the near offset, which is often a concern in 3D SRME. This is an added advantage because using the dataset as input for imaging would result in final products that are consistent for improved structural and stratigraphic interpretation, and attribute analysis.

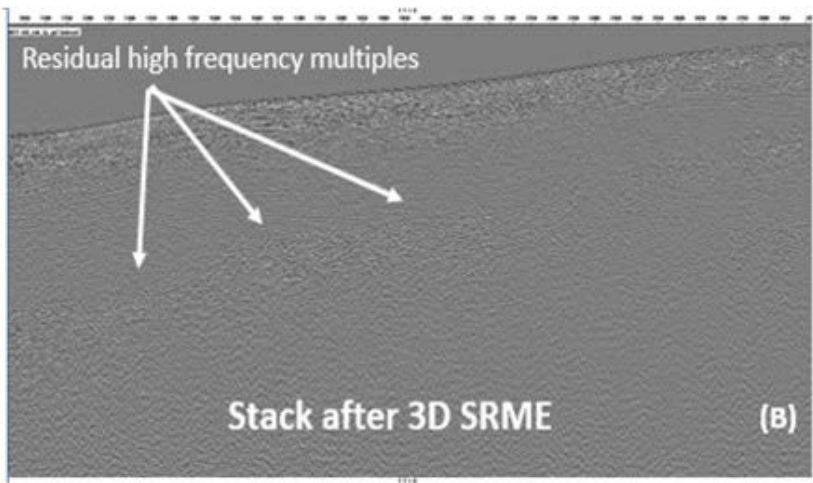

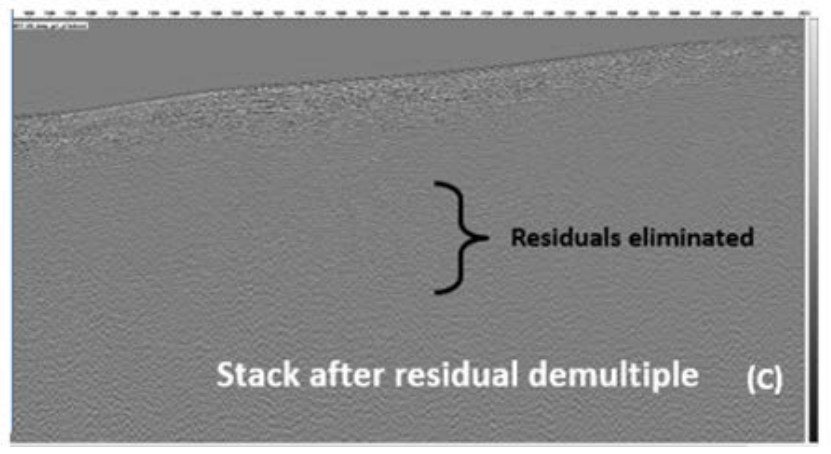

Figure 7. Comparison of the multiple elimination products - stack input to 3D SRME multiple modeling and subtraction (a), stack after adaptive subtraction (b) showing evidence of residual high frequency multiples, and stack after attenuation of residual multiples (c). The 3D SRME behaved as expected in leaving some high-frequency residuals in the data. This is a limitation in the procedure due to limited aperture around data boundaries. The post 3D SRME demultiple was effective in eliminating the residuals 

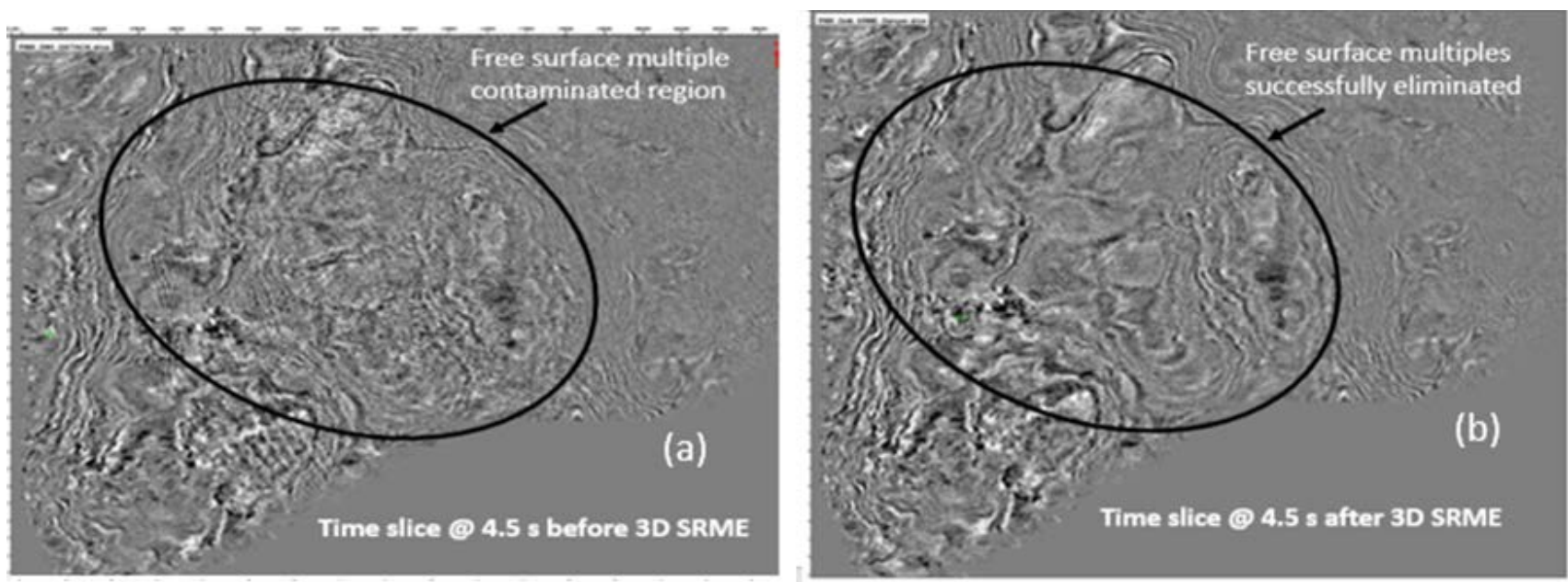

Figure 8. Time slice at $4.5 \mathrm{~s}$ showing (a) input dataset to 3D SRME and (b) post 3D SRME residual demultiple product. The displays show effectiveness of the method in attenuating free surface multiples in the dataset

\section{Conclusion}

The foregoing is a case study of free surface multiple modeling and removal on partially processed 3D seismic data from the Niger Delta offshore using the method of 3D SRME. The technique we employed enabled us to derive an aperture for all possible downward bounce locations on the air-water interface to carry out convolution. We also deployed a multiple trace interpolation technique which resulted in complete and successful infill of the near offsets prior to the multiple modeling and subtraction. The method was successful in attenuating multiples up to 60 $\mathrm{Hz}$, but had limitation in completely attenuating some high frequency free surface multiples around data boundaries where the 3D SRME had limited aperture. The residual multiples were eliminated by the deployment of a technique which compares amplitudes of the multiples in frequency panels to some reference thresholds in such a way that the amplitudes can be clipped when necessary. The 3D SRME demultiple approach used in this case study produce final deliverables that are consistent for DHI/AVO analyses, structural and stratigraphic interpretation and attribute analyses.

\section{References}

[1] Xiao, C., Bancroft, J.C., Brown, R.J. and Cao, Z. Multiple suppression: A literature review, CREWES Research Report, Vol. 15, 2003.

[2] Huang, X., Sun, C., Niu, B., Wang, H. and Zeng, M.. Surface multiple prediction and suppression based on data-consistence: A theoretical study, Chinese Journal of Geophysics, 48(1), pp. 188-196, 2005.

[3] Dragoset, W.H. and Jericevic, Z. Some remarks on surface multiple attenuation: Geophysics, 63, 772-789, 1998.

[4] Dragoset, B. A practical approach to surface multiple attenuation, The Leading Edge, 18, 104-108, 1999.

[5] Meles, G.A., Loer, K. Ravasi, M. and da Costa Filho, C., 2015, Internal multiple prediction - A new approach based on seismic interferometry and Marchenko autofocusing, $77^{\text {th }}$ EAGE Annual Conference \& Exhibition, Madrid, Spain.

[6] Verschuur, D.J., Berkhout, A.J. and Wapenaar, C.P.A. Adaptive surface-related multiple elimination: Geophysics, 57, 1166-1177, 1992.

[7] Verschuur, D. J. and Prein, R. J. Multiple removal results from Delft Unversity: The Leading Edge, 18, 86-91, 1999.
[8] Berndt, C. and Moore, G.F. Dependence of multiple-attenuation techniques on the geologic setting: A case study from offshore Taiwan, The Leading Edge, 18, 74-80, 1999.

[9] Wu, M. and Wang, S. A case study of f-k demultiple on 2D Offshore seismic data, The Leading Edge, pp. 446-450, 2011, April.

[10] Ogagarue, D.O. and Ebeniro, J.O., Water bottom multiple elimination and data quality enhancement using parabolic radon transform: A case study of 3D seismic data from offshore Niger Delta, Journal of Geosciences and Geomatics, Vol. 2(4), pp. 172-177, 2014.

[11] Berkhout, A.J., 1985, Seismic migration imaging of acoustic Energy by wave field extrapolation (3rd Edition), AE Amsterdam: Elsevier Science Publ. Co.

[12] Wiggings, J.W., 1985, A demonstration of long-period multiple attenuation to wave extrapolation, $55^{\text {th }}$ Ann. Intern. Mtg. Soc. Of Expl. Geophys., Session: S20. 5.

[13] Zhou, B. and Greenhalgh, S.A. A wave-equation extrapolationbased multiple attenuation: 2D filtering in the $\mathrm{f}-\mathrm{k}$ domain, Geophysics, 59, pp. 1377-1391, 1994.

[14] Anstey, N.A. and Newman, P. The sectional auto-correlogram and Part II: The sectional retro-correlogram, Geophys. Prospecting., 14, pp. 391-426, 1967.

[15] Riley, D.C. and Claerbout, J.F. 2-D multiple reflections, Geophysics, 41, pp. 592-620, 1976.

[16] Kennett, B.L. The suppression of surface multiples on seismic records, Geophysics. Prospecting., 27, pp. 584-600, 1979.

[17] Berkhout, A.J. and Versechuur, D.J. Estimation of multiple scattering by iterative inversion, part I: Theoretical considerations, Geophysics, 62, pp. 1586-1595, 1997.

[18] Versechuur, D.J. and Berkhout, A.J. Estimation of multiple scattering by iterative inversion, part II: Practical aspects and examples, Geophysics, 62, pp. 1596-1611, 1997.

[19] Kokstad, H. and Sollie, R., 1999, 3-D surface related multiple elimination using parabolic radon transform, SEG Extended Technical Program Abstracts, January.

[20] Biersteker, J., 2001, MAGIC: Shell's surface multiple attenuation technique, $71^{\text {st }}$ Intern. Mtg., Soc. Expl. Geophys., Expanded Abstracts, 1301-1304.

[21] Kleemeyer, G., Pettersson, S.E., Eppenga, R., Haneveld, C.J., Biesteker, J. and den Ouden, R., 2003, It's Magic - Industry first 3D surface related multiple elimination and pre-stack depth migration on Ormen Lange, 65 ${ }^{\text {th }}$ Mtg.: Eur. Assn. Geosci. Eng., B43.

[22] Lin, D., Young, J. and Huang, Y., 2004, 3D SRME application in the Gulf of Mexico, $66^{\text {th }}$ Mtg.: Eur. Assn. Geosci. Eng.

[23] Van Dedem, E.J. and Versechuur, D.J., 2001, 3-D surface related multiple prediction using sparse inversion, $71^{\text {st }}$ Intern. Mtg.: Soc. Expl. Geophys., Expanded Abstracts, 1285-1288.

[24] Matson, K.H., Paschal, D. and Weglein, A.B. A comparison of three multiple attenuation methods applied to a hard water-bottom data set, The Leading Edge, 18, pp. 120-126, 1999.

[25] Burke, K. Longshore drift, submarine canyons, and submarine fans in development of Niger Delta: American Association of Petroleum Geologists, v. 56, p. 1975-1983, 1972. 
[26] Evamy, B.D., Haremboure, J., Kamerling, P., Knapp, W.A., Molloy, F.A. and Rowlands, P.H. Hydrocarbon habitat of the Niger Delta, American Association of Petroleum Geologists
Bulletin 62, pp.1-39, 1978.

[27] Shorte, K.C. and Stauble, A.J. Outline of the Geology of Niger Delta, AAPG Bulletin, 51, 761-779, 1967. 